\title{
Factors affecting fertility decisions of married men and women living with HIV in South Wollo Zone, Northeast Ethiopia
}

\author{
Menberu Getachew ${ }^{1}$, Fessehaye Alemseged ${ }^{2}$, Mulumebet Abera ${ }^{3}$, Amare Deribew ${ }^{4}$
}

\begin{abstract}
Background: In a setting with high HIV prevalence and high fertility rates, addressing fertility issues of People Living with HIV/AIDS (PLWHA) is crucial. However, understanding of the factors associated with fertility decisions of PLWHA in Ethiopia is remarkably low.

Objective: The study was conducted to assess factors associated with fertility decisions of PLWHA in South Wollo Zone, Northeast Ethiopia.

Methods: The study was conducted from February 1 to March 30, 2008 using cross-sectional design. Quantitative data were collected from a sample of 458 men and 458 women using structured questionnaire. Qualitative data were also collected from six health care providers. Logistic regression was used to analyze the quantitative data.

Results: The study showed that $18.3 \%$ of currently married PLWHA have decided to have a child. The factors found to be independently associated with current decision to have a child were higher family income [OR $(95 \% \mathrm{CI})=2.29$ $(1.23,4.26)]$, partner's decision to have a child $[\mathrm{OR}(95 \% \mathrm{CI})=36.4(17.0,77.5)]$, having knowledge on PMTCT [OR $(95 \% \mathrm{CI})=2.26(1.44,3.54)]$ and having partner with negative HIV test result [OR $(95 \% \mathrm{CI})=0.408(0.219,0.759)]$. During in-depth interview the health care providers indicated the fertility related counseling service to be low.

Conclusion: In spite of the fact that significant proportion of married PLWHA had decided to have a child, the fertility related counseling service is low. Improving fertility related counseling services to enable clients make informed fertility decision is mandatory. The factors identified to be associated with fertility decision could be of major importance and as such should be investigated further. [Ethiop. J. Health Dev.2010;24(3):214-220]
\end{abstract}

\section{Introduction}

An estimated 33.2 million people worldwide were living with HIV at the end of 2007. Out of these an estimated 22.5 million HIV infected people live in Sub-Saharan Africa (1). The infection rate among pregnant women in Sub-Saharan Africa is also alarmingly high, where $90 \%$ of global new child infections through mother-to-child transmission (MTCT) occur (2). With 1,320,000 million people living with HIV/AIDS (PLWHA), Ethiopia is one of the countries most heavily affected by the epidemic, heterosexual HIV transmission being the main route followed by mother to child transmission (3).

The desire and intent to have children among HIVinfected individuals may increase because of improved quality of life and survival following commencement of anti-retroviral treatment and reproductive health service as well (4). The fact that many HIV infected adults desire and expect to have children in the future has significant implication for the prevention of HIV transmission to sexual partner, the new born and future demand of social services for children born to infected parents (1). It has been widely recognized that significant and major investments must be made for sexual and reproductive health services to PLWHA (5).
In line with this, Ethiopia, has adopted the WHO/UNICEF/UNAIDS 4-pronged Prevention of Mother to Child Transmission of HIV (PMTCT) strategy as a key entry point in order to expand coverage and deliver simple as well as effective PMTCT interventions in all settings even with limited capacity (6). Where as, owing to numerous factors, awareness of mother-to-child transmission of HIV is generally low, the uptake of PMTCT services is limited and only a small proportion of $\mathrm{HIV}$-infected pregnant women actually benefit from PMTCT services (3).

Ethiopia is characterized by high fertility that is culturally valued, high HIV prevalence, low levels of contraceptive use and significantly higher intentions to have a child in the general population with a higher preference among men (63\%) than women (55\%) (2). In a background of this fact, addressing fertility issues of PLWHA is critical. However, competing for resources with other needs, provision of comprehensive Sexual and Reproductive Health (SRH) care for PLWHA has been given low priority. Services are often characterized by poor integration, low quality of client-provider

\footnotetext{
TEngender Health Ethiopia, Dessie Satellite Office, E-mail meene97@yahoo.com, menberugetachew@gmail.com, Tel 251912948599, P.O. Box 1035, Dessie, Ethiopia;

${ }^{2}$ Deparmtn of Epidemiology, Jimma University, Jimma, Ethiopia;

${ }^{3}$ Poulation and Family Health Department, College of Public Health and Medical Sciences, P.O. Box 5093 Jimma University, Jimma, Ethiopia;

${ }^{4}$ Danartmont of Fnidaminloner Timma Inivarcitr Timma Fthinnis
} 
interaction, high levels of stigma and discrimination and limited access particularly by vulnerable groups (7).

Moreover, only few studies highlighted on PLWHA's fertility decision pattern (8) and available researches in the country in the country in general and in the study area in particular didn't address the factors associated with fertility decisions and their implication for intervention programmes. Hence this study was conducted to assess the pattern of and identify factors, which play a role for fertility decision of PLWHA.

\section{Methods}

The study area is located in South Wollo Zone, Amahara Regional State in Northeastern part of Ethiopia. According to the national population and housing census of Ethiopia, the projected population of the zone for $2007 / 2008$ was estimated to be $3,036,532$. The area has 3 hospitals, 39 health centers and 270 functioning health posts with estimated potential health service coverage of $91 \%(9)$.

A facility based cross-sectional comparative study consisting of both qualitative and quantitative methods was employed to assess factors associated with decision to have a child among married PLWHA from January 15, 2008 to March 15, 2008. This study covered all the three hospitals (Dessie, Boru and Akesta) and five health centers (Dessie, Kombolcha, Haik, Mekaneselam and Woreilu) which were providing pre-ART and ART follow-up services. Since the start of ART in the Zone, about 19,702 HIV positive clients were enrolled in preART counseling and ART service in the eight health institutions (9).

For the quantitative study, all married PLWHA between ages 15-59 years attending ART and pre-ART counseling service were considered to be the source population. The age limits were taken from the Ethiopian Demographic and Health Survey (EDHS) owing to the relevance of those age limits to fertility preferences in Ethiopian context. From 19,702 total PLWHAs in the Zone, 1892 were married (982 men and 910 women). List of married clients was prepared from the pre-ART counseling and ART service registration books and client's cards of the respective health institution. The exclusion criteria for study subjects included: terminally ill and disabled people who cannot respond for the interview, clients who had undergone tubal legation and/or partner had undergone vasectomy, clients who are known to be infertile, women who were pregnant before the knowledge of their HIV sero-status and clients who didn't have at least one visit of ART clinic prior to data collection. And the qualitative study included purposively selected counselors from each health unit.

The sample size was determined using Epi info version 6.04 taking $44.7 \%$ fertility desire for women and $35.2 \%$ for men (14) and 1:1 proportion for each group, $95 \%$ confidence level $(\alpha=0.05), 80 \%$ power and $10 \%$ nonresponse giving a total sample size of 962 , which is 481 for each group. The calculated sample size was distributed proportionally to the 8 public health institutions. Then simple random sampling was used to select the study subjects. For qualitative method six counselors were included in the in-depth interview as saturation of information was achieved.

Data were collected using a pre-tested structured questionnaire, which was originally prepared in English and then translated to the local language, Amharic. The dependent variable was decision to have a child which was defined as current wanted pregnancy and/or current practice/effort to have a child after the knowledge of positive sero status. The independent variables were socio-demographic characteristics; ART status and HIV related disease condition; clients knowledge on MTCT and previous pregnancy outcomes; and partner and service-related factors.

Ten trained nurse counselors were involved in the quantitative data collection and the principal investigator collected the qualitative data. The data collection was supervised by the principal investigator and two supervisors. The counselors interviewed HIV positive clients and the principal investigator interviewed health professionals. Data were collected through face-to-face interview with the study subjects.

The data were cleaned, coded and fed to Statistical Package for Social Sciences (SPSS) version 12.0.1. Simple frequencies were used to see the overall distribution of the study subjects with regard to the variables under study. Chi square and Odds ratio were used to determine the association between hypothesized independent and dependent variables. Finally, logistic regression was used to control possible confounders and identify independent predictors of fertility decision. Fertility decision was operationally defined as having current planned pregnancy and/or current practice or effort to have a child. A significance level of 0.05 was used to decide the significance of statistical tests. Qualitative data were transcribed and analyzed along major themes.

Ethical clearance was obtained from Ethical clearance committee of Jimma University (JU) and permission was obtained from the officials of the studied health institutions before commencing the research. More importantly informed consent was obtained from all participants and confidentiality of the data as well as anonymity was ensured.

\section{Results}

A total of 916 (458 married men and 458 married women) respondents were included in the study with response rate of $95.2 \%$ and six in-depth interviews were undertaken with health care providers. 
Socio-demographic characteristics: Three hundred eighty six $(42.1 \%)$ of participants were in the age group 30-39 years. The mean age of the respondents was 32.74 \pm 7.73 years. Majority $(58 \%)$ of the participants were Muslim in their religion followed by Orthodox Christians (39.5\%). Concerning residential area, 73\% were from the urban setting. In terms of educational status, $34.1 \%$ of the study participants have completed secondary school.

ART status and HIV related disease condition: Majority (61\%) of participants had duration of up to 1 year since HIV diagnosis. About $86 \%$ were on ART and the rest $(13.8 \%)$ were on pre-ART counseling service. Among those who were on ART, 90.8\% reported improved health condition after ART initiation (Table $1)$.

Table 1: ART status and HIV related disease condition of study subjects, South Wollo Zone, 2008

\begin{tabular}{ll}
\hline Variables & $\begin{array}{c}\text { Frequency } \\
(\mathbf{N}=916) \mathbf{N}(\%)\end{array}$ \\
\hline Duration since HIV Diagnosis & \\
1-12 months & $561(61.2)$ \\
$>12$ months & $355(38.8)$ \\
Starting ART & \\
Yes & $790(86.2)$ \\
No & $126(13.8)$ \\
Duration since ART & $(\mathrm{N}=790)$ \\
1-12 months & $516(65.1)$ \\
$>12$ months & $277(34.9)$ \\
Self reported health status after & $(\mathrm{N}=790)$ \\
ART & \\
Improved & $718(90.8)$ \\
No change/ Aggravated & $72(9.2)$ \\
Current CD4 count & \\
1-200 & $397(43.3)$ \\
$>200$ & $34(37.2)$ \\
Unknown & $178(29.5)$ \\
\hline
\end{tabular}

Knowledge about PMTCT: With regard to knowledge about PMTCT $66.7 \%$ of the total participants were found to be knowledgeable. Only $37 \%$ of currently pregnant women attended PMTCT follow up service. Some of the reasons mentioned for non-attendance were: don't know about PMTCT (68.8\%), pregnancy was unwanted (10.4\%), no family/friends support $(4.2 \%)$ and fear of stigma/discrimination $(6.2 \%)$.

Counselors also expressed problems related to PMTCT follow up service attendance by clients.

"...For a better off family it is good to try the Nevirapine short course treatment, I believe that the family can reduce the risk of transmission of HIV during breast-feeding. Other wise we may contribute a lot to child HIV prevalence as most mothers missed the follow up program, and during delivery mother prefer home than health institution".(Nurse counselor).

Partner characteristics: More than $93 \%$ of study participants disclosed their HIV status to their partner.
About 23\% of the respondents' partners were seronegative. Nearly $41 \%$ of the respondents reported that their partners had desire to have a child, $47 \%$ reported their partners had no desire to have a child and $12 \%$ didn't know their partner's fertility desire (Table 2 ).

Status of fertility related counseling services: About $83 \%$ of the total participants want to discuss about fertility related issues with their counselors in the ART clinic. $59 \%$ of those in need have got the counseling service. About $22 \%$ of those who got counseling reported that the counseling services provided by the counselors were inadequate. Participants of the qualitative study also reported about the inadequacy of the services. A nurse counselor replied in this regard as;

“... They prefer to receive all the services including medical care from our clinic. Even we know they will not go to other service centers out of the ART clinic because they feel shame and are afraid of the community even health workers, fear of social stigma and discrimination as most of them didn't disclose their status even to their partner".

Table 2: Partner Characteristics of study subjects attending ART and pre-ART counseling services, South Wollo Zone, 2008

\begin{tabular}{ll}
\hline Variables & $\begin{array}{l}\text { Over all } \\
(\mathbf{N}=916)\end{array}$ \\
\hline $\begin{array}{l}\text { Duration of stay with partner } \\
<2 \text { years }\end{array}$ & $\mathrm{N}(\%)$ \\
$2-5$ & $159(17.3)$ \\
$>5$ years & $675(73.7)$ \\
$\begin{array}{l}\text { Partner's fertility desire } \\
\text { Yes }\end{array}$ & $373(40.7)$ \\
No & $433(47.3)$ \\
Don't know of HIV status to & $110(12)$ \\
Disclosure & \\
partner & \\
Yes & $857(93.5)$ \\
No & $59(6.5)$ \\
$\begin{array}{l}\text { Partner tested for HIV } \\
\text { Yes }\end{array}$ & \\
No & $744(81.2)$ \\
Don't know & $130(14.2)$ \\
HIV test result of Partner & $42(4.6)$ \\
Negative & $(\mathrm{n}=744)$ \\
Positive & $174(23.3)$ \\
& $570(76.7)$ \\
\hline
\end{tabular}

Further more, they commented on the current status of the counseling service provided for PLWHA as inadequate, demand driven, and staffed with only few and poorly trained manpower.

"Generally, the RH services for PLWHA are inadequate. Because there are missed opportunities to provide comprehensive counseling services in issues like fertility and FP. Irregular $R H$ services provided are demand driven; otherwise we are not providing those services with out their request; of course mainly due to burden of work and some times negligence". (Nurse counselor). 
Fertility related characteristics: Concerning desire to have a child, $18.3 \%$ have decided to have a child currently and $36.4 \%$ have future desire to have a child and the number of children desired in the future ranges from 1 to 6 . About $7 \%$ of the respondents or respondents' partners had at least one pregnancy after HIV diagnosis among which $38 \%$ were not planned. Nearly $61 \%$ of those who did not have fertility related decisions at the time of the study were not using any method of birth control (Table 3). A counselor working in a hospital also reinforced this idea as:

"Though PLWHA inform us about their decision not to have a child, in reality they become pregnant. And this happens mainly because both partners usually do not come to get counseling and testing at the same time to get at a common decision".

Table 3: Fertility related Characteristics of currently married men and women attending ART and pre-ART counseling services, South Wollo Zone, 2008

\begin{tabular}{|c|c|}
\hline Variables & $\begin{array}{l}\text { Frequency } \\
\text { No (\%) }\end{array}$ \\
\hline \multicolumn{2}{|l|}{$\begin{array}{l}\text { Current Fertility decision to have } \\
\text { a child }\end{array}$} \\
\hline $\begin{array}{l}\text { Yes } \\
\text { No }\end{array}$ & $\begin{array}{l}175(18.3)^{*} \\
74(79.5)\end{array}$ \\
\hline \multicolumn{2}{|l|}{ Future desire to have a child } \\
\hline Yes & $333(36.5)$ \\
\hline No & $583(63.7)$ \\
\hline $\begin{array}{l}\text { Desired number of children } \\
(n=333)\end{array}$ & \\
\hline One & $123(37.4)$ \\
\hline Two \& above & $204(61.2)$ \\
\hline $\begin{array}{l}\text { Previous pregnancy after HIV } \\
\text { diagnosis }\end{array}$ & \\
\hline Yes & $66(7.2)$ \\
\hline No & $850(92.8)$ \\
\hline \multicolumn{2}{|l|}{$\begin{array}{l}\text { Previous pregnancy out come } \\
(n=66)\end{array}$} \\
\hline Live birth & $42(63.6)$ \\
\hline Still birth/abortion & $24(36.4)$ \\
\hline \multicolumn{2}{|l|}{ Current pregnancy } \\
\hline Yes & $75(8.2)$ \\
\hline No & $841(91.8)$ \\
\hline $\begin{array}{l}\text { Current } \\
(n=75)\end{array}$ & \\
\hline Yes & $41(54.6)$ \\
\hline No & $34(45.4)$ \\
\hline
\end{tabular}

*Weighted only for current fertility decision
Correlates of fertility decision: This relationship of fertility decision with hypothesized independent variables was examined for 175 married men and women who had current planned pregnancy and/or current practice or effort to have a child.

In the bivariate analysis, among the socio-demographic variables, sex, age, religion, educational status, employment, monthly income and number of children were found significantly associated with fertility decision. Among the partner related variables, duration of stay with current partner, HIV status disclosure to partner, whether partner was tested or not, Partner's fertility desire and partner's HIV test result were found significantly associated. With regard to ART status and HIV related disease condition variables, duration since HIV diagnosis and self-reported health status were found significantly associated. In addition from PMTCT knowledge and counseling status variables knowledge was significantly associated with fertility decision.

After controlling for possible confounders however, male sex [AOR, $(95 \% \mathrm{CI}), 1.78(1.15,2.74)]$, higher family income [AOR, $(95 \% \mathrm{CI}), 2.29(1.23,4.26)]$, partner's fertility desire [AOR, $(95 \% \mathrm{CI}), 36.4(17.0$, 77.5)] and good knowledge on PMTCT [AOR, (95\% CI), $2.26(1.44,3.54)]$ were positively associated with having fertility decision at the time of study, whereas partner's negative HIV test result [AOR, $(95 \% \mathrm{CI})$, $0.408(0.219,0.759)]$ was negatively associated with having fertility decision at the time of the study (table 4). 
Table 4: Factors associated with fertility decisions of study participants, South Wollo Zone, 2008.

\begin{tabular}{|c|c|c|c|c|}
\hline \multirow[t]{2}{*}{ Variables } & \multicolumn{2}{|c|}{ Fertility decision $(\mathrm{N}=916)$} & \multirow[t]{2}{*}{ COR $(95 \% \mathrm{CI})$} & \multirow[t]{2}{*}{ OR $(95 \% \mathrm{Cl})$} \\
\hline & Yes (\%) & No $(\%)$ & & \\
\hline \multicolumn{5}{|l|}{ Sex } \\
\hline Men & $103(22.4)$ & $355(77.6)$ & $1.55(1.114,2.172)^{\star *}$ & $1.78(1.15,2.74)^{\star *}$ \\
\hline Women & $72(15.7)$ & $386(84.3)$ & 1 & \\
\hline \multicolumn{5}{|l|}{ Age } \\
\hline $15-29$ & $77(22.3)$ & $260(77.7)$ & $1.619(1.017,2.577)^{*}$ & \\
\hline $30-39$ & $68(17.6)$ & $317(82.4)$ & $1.173(734,1.875)$ & \\
\hline 40 and above & $30(15.4)$ & $164(84.6)$ & 1 & \\
\hline \multicolumn{5}{|l|}{ Religion } \\
\hline Christian & $62(16)$ & $325(84)$ & 1 & \\
\hline Muslim & $113(21.3)$ & $416(78.7)$ & $(1.011,2.005)^{*}$ & \\
\hline \multicolumn{5}{|l|}{ Education } \\
\hline Informal education & $26(11)$ & $210(89)$ & 1 & \\
\hline Formal, Primary \& above & $149(22)$ & $531(78)$ & $2.266(1.451,3.541)^{* *}$ & \\
\hline \multicolumn{5}{|l|}{ Occupation } \\
\hline Employed & $121(22)$ & $426(78)$ & $1.657(1.165,2.357)^{*}$ & \\
\hline Unemployed & $54(14.6)$ & $315(85.3)$ & & \\
\hline \multicolumn{5}{|l|}{ Monthly income } \\
\hline $0-500$ & $143(17.6)$ & $668(82.4)$ & 1 & \\
\hline$>500$ & $32(32.4)$ & $73(67.6)$ & $2.048(1.302,3.22)^{\star *}$ & $2.29(1.23,4.26)^{\star *}$ \\
\hline \multicolumn{5}{|l|}{ Number of children } \\
\hline 0 & $61(34.8)$ & $114(65.2)$ & $2.47(1.57,3.89)^{* *}$ & \\
\hline 1 and above & $114(15.3)$ & $627(84.7)$ & 1 & \\
\hline \multicolumn{5}{|c|}{ Duration of stay with partner } \\
\hline $0-5$ years & $71(29.4)$ & $170(70.6)$ & 1 & \\
\hline$>5$ years & $104(15.4)$ & $571(84.6)$ & $.436(.308, .617)^{\star *}$ & \\
\hline \multicolumn{5}{|l|}{ Disclosure to partner } \\
\hline Yes & $171(18.7)$ & $686(74.9)$ & $3.427(1.22,9.58)^{*}$ & \\
\hline No & $4(.4)$ & $55(6)$ & 1 & \\
\hline \multicolumn{5}{|l|}{ Partner's fertility desire } \\
\hline Yes & $157(42.9)$ & $216(57.1)$ & $21.23(12.65,35.43)^{* * *}$ & $36.4(17.0,77.5)^{\star *}$ \\
\hline No & $18(3.3)$ & $525(96.7)$ & 1 & \\
\hline \multicolumn{5}{|c|}{ Partners HIV test result $\mathrm{N}-914$} \\
\hline Negative & $14(8.6)$ & $159(91.4)$ & $0.298(.170,0.524)^{\star \star \star}$ & $0.408(0.219,0.759)^{* *}$ \\
\hline Positive & $137(18.5)$ & $433(81.5)$ & & \\
\hline \multicolumn{5}{|c|}{ Duration since HIV diagnosis } \\
\hline $1-12$ months & $95(16.9)$ & $466(83.1)$ & 1 & \\
\hline$>12$ months & $80(20.7)$ & $275(79.3)$ & $1.427(1.023,1.990)^{*}$ & \\
\hline \multicolumn{5}{|l|}{ Self reported health status } \\
\hline Improved & $152(18.9)$ & $576(71.5)$ & $20.34(2.82,147.22)^{\star *}$ & \\
\hline No change/Aggravated & $1(.1)$ & $77(9.6)$ & & \\
\hline \multicolumn{5}{|l|}{ Knowledge about PMTCT } \\
\hline Knowledgeable & $125(24.2)$ & $391(75.8)$ & $2.23(1.56,3.20)^{* *}$ & $2.26(1.44,3.54)^{*}$ \\
\hline Non knowledgeable & $50(12.5)$ & $350(87.5)$ & 1 & \\
\hline
\end{tabular}

Note: ${ }^{* \star} \mathrm{P}<0.001,{ }^{* *} \mathrm{P}<0.01$ and ${ }^{*} \mathrm{P}<0.05$

\section{Discussion}

Addressing fertility issues among PLWHA is crucial for prevention of unwanted pregnancies and MTCT especially with advance in treatment which changes views of fertility intention and childbearing despite having the disease $(2,4,10)$. This study has tried to look into fertility desire of PLWHA and associated factors.

Over all $18.3 \%$ of the total participants decided on fertility to have a child. The study revealed significant differences between men and women in their fertility decision pattern. Men were found almost twice more likely to decide on fertility than women [AOR, 95\% CI, $1.78(1.15,2.74)](p<0.01)$. This finding is higher than the study conducted in Uganda (16\%) and consistence in its pattern in that men were almost four times more likely to want more children than women (11). The study also revealed that current fertility decision among men was lower than a study conducted in Brazil $(50.1 \%)$. Likewise, women's fertility decision was lower than studies in Zimbabwe (54\%), comparable with the study in Brazil (19.2\%) but lower than the study in Uganda (7\%) (12-14). This difference could be attributable to the difference in the operational definitions used. That is also why client's current fertility decision in this study was also lower when compared to a similar study conducted in Addis Ababa where $(44.7 \%)$ of female and $(35.2 \%)$ of the male respondents expressed the desire for children (8).

The qualitative study result showed that women specially from the rural community seemed more worried for the stigma related fears and desertion from their husband; as highlighted by counsellors, confusions 
as to how to sustain life with their husband with out producing a child is being the usual worry of women participants; there fore imposed to conceive regardless of their desire.

Income as a predictor of the over all fertility decision, participants whose families monthly income was above 500 Birr were 2.3 times more likely to made fertility decision than those with monthly income of $<500$ Birr [AOR, 95\%CI, 2.29 (1.23, 4.26)], $(\mathrm{P}<0.05)$. The study in Zambia also identified income as the most important and most common factor that influenced childbearing decisions (13). This could be due to the fact that PLWHA with better income may feel that they could have the opportunity for better care of their child.

Partner fertility desire was also an important determinant of the current fertility decision in this study. This was in agreement with the study in Addis Ababa and Zimbabwe $(9,14)$. This could be due to better opportunity to discuss on fertility related decisions among couples. On the other hand, as of the descriptive study results, client's partners fertility desire was found much higher than the decision of the clients them selves which could be partly due to the non-disclosure to partner.

This was evidenced by the in-depth interviews with the counsellors. One counselor from a rural health center expressed her view on the current situation of fertility preference of PLWHA as: "As compared with the previous years, more pregnancies are recognized even after they know their status. Of course, considerable proportion of women also reported unwanted pregnancies". A counselor working in a Hospital also reinforced this idea as; "Though PLWHA inform us they do not want to have a child but in reality they become pregnant. And this happens mainly because both partners usually do not come to get counselling and testing at the same time so they may not disclose their result and get common decision".

Many of the couples were with discordant serostatus $(24.3 \%)$, which is lower than the study in Addis Ababa $(31.5 \%)$ and higher than a study in London $(21.9 \%)$. And nearly $10 \%$ of the sero-discordant partners still decided to have a child; the study result showed that, participants whose partner's test result was negative were $63 \%$ less likely for fertility decision than with positive result [AOR, 95\% CI $0.366(0.193,0.907)]$, $(\mathrm{P}<0.001)$. This is in line with other studies conducted in Uganda (11). This could be due to fear of infecting their partner, which could raise an issue of SRH right of PLWHA. More over, the issue of conception would be particularly important as means to avoid partner infection should be paramount that needs consideration on alternative options/technologies.
Clients who were knowledgeable on PMTCT were about two times more likely for fertility decision than the non-knowledgeable ones [AOR, 95\% CI 2.26 (1.44, 3.54)], $(\mathrm{P}<0.01)$. The result goes in line with other studies $(10,12,15)$. A study in South African, indicated that the availability of PMTCT would influence PLWHA in favour of having children, sometimes wishing to replace a departed child or ensure that the child will not be infected (4).

In conclusion, considerable number of PLWHA wants to have a child currently or in the near future. Many sociodemographic variables, partner related variables, ART status and HIV related disease condition variables, and knowledge about PMTCT were significantly associated with fertility decision. Most of the study participants felt that health care providers were not adequately skilled in addressing the reproductive needs of their clients. Therefore, this may require improving the skills of the health care providers to enable them to adequately address the needs of their clients.

\section{Acknowledgments}

We would like to acknowledge Jimma University for funding the research. Our thanks also go to South Wollo Zone ART clinic staff members for their unreserved effort during the data collection time. Last but not least the study participants are appreciated for their interest and full participation shown in the study.

\section{References}

1. UNAIDS and WHO. AIDS epidemic update. December 2006. Geneva: UNAIDS and WHO; 2007.

2. Central Statistical Agency [Ethiopia] and ORC Macro [USA]. Ethiopia Demographic and Health Survey 2005. Addis Ababa, Ethiopia; CSA; 2006.

3. Federal HIV/AIDS Prevention and Control Office. AIDS in Ethiopia: Technical document for the sixth report, 2006. Addis Ababa, Ethiopia: FMOH; 2006.

4. Cooper D, Bracken H, Myer L, Zweigenthal V, Harries J, Orner P, et al. Reproductive intentions and choices among HIV-infected individuals in Cape Town, South Africa: Lessons for reproductive policy and service provision from a qualitative study. Women's Health Research Unit, University of Cape Town (UCT), Infectious Diseases Epidemiology Unit, UCT and Population Council, New York City; September 2005.

5. WHO and UNFPA. Sexual and reproductive health of women living with HIV/AIDS: Guidelines on care, treatment and support for women living with HIV/AIDS and their children in resourceconstrained settings. Geneva: WHO; 2006.

6. Federal HIV/AIDS Prevention and Control Office. Guidelines for prevention of mother-to-child transmission of HIV in Ethiopia. 2007. Addis Ababa, Ethiopia; FMOH; 2007. 
7. Perchal P. Farrell B and Osborne K. Responding Sexual and Reproductive Rights of PLWHIV. Global AIDS Link; 2006.

8. Tamene W, Fantahun M. Fertility desire and family planning demand among HIV-positive women and men undergoing antiretroviral treatment in Addis Ababa, Ethiopia. Africa $J$ of AIDS Res 2007;6(3):223-227.

9. South Wollo Zone Health office. Annual Report for 1999E.C. Dessie, Ethiopia; South Wollo Zone Health office; June 2007.

10. Stanwood N. Cohn S. Heiser J and Pugliese M. Contraception and fertility plans in a cohort of HIVpositive women in care. Contraception 2007;75; 294-298.

11. Nakayiwa S, Abang B, Packel L, Lifshay J, Purcell $\mathrm{DW}$, King $\mathrm{R}$, et al. Desire for children and pregnancy risk behavior among HIV-infected men and women in Uganda. AIDS Behav 2006;2:437448 .
12. Paiva V. Santos N. França-Junior I. Filipe E. Ayres $\mathrm{J}$ and Segurado A. Desire to Have Children: Gender and Reproductive Rights of Men and Women Living with HIV: A Challenge to Health Care in Brazil. AIDS Patient Care and STDs 2007;21(4): 268-277.

13. Rutenberg N. Biddlecom A and Kaona F. Reproductive Decision-Making in the Context of HIV and AIDS: A Qualitative Study in Ndola, Zambia. International Family Planning Perspectives 2000;26(3):124-130.

14. Chen J. Phillips K, Kanouse D. Collins R and Miu A. Fertility desires and intentions of HIV positive men and women. International Family Planning Perspectives 2001;33(4):144-152 and 165.

15. Yacouba N, Nicolas M, Valériane L, Laurent M, Seydou Y, Issiaka S, et al. Sexual and Reproductive Life of Women Informed of Their HIV Seropositivity: A Prospective Cohort Study in Burkina Faso. J Acquir Immune Defic Synd 2001;28:367372. 